\title{
How and When Leisure Crafting Enhances College Students' Well-Being: A (Quantitative) Weekly Diary Study
}

\author{
Qing Xue', Jinxin Yang ${ }^{2}$, Huatian Wang ${ }^{3}$, Deyu Zhang ${ }^{4}$ \\ 'Shandong Youth University of Political Science, Jinan, People's Republic of China; '2University of Jinan, Jinan, People's Republic of China; ${ }^{3}$ Industrial \\ Engineering and Innovation Science, Eindhoven University of Technology, Eindhoven, the Netherlands; ${ }^{4}$ College of Foreign Languages, Ocean \\ University of China, Qingdao, People's Republic of China
}

Correspondence: Huatian Wang, Eindhoven University of Technology, De Zaale, Eindhoven, 5600 MB, the Netherlands, Tel +3I 0402479 III, Email h.wang4@tue.nl

Purpose: College students' well-being is important for their self-growth and the whole society. However, we still know relatively little about how college students could proactively, strategically improve their well-being in the leisure context. Following the selfdetermination theory and proactivity literature, this study examines how and when leisure crafting (ie, a proactive act whereby individuals balance their leisure resources and demands by utilizing their personal abilities and needs) can enhance college students' well-being.

Methods: Conducting a quantitative weekly diary study of 80 Chinese students in an engineering college (320 observations), we drew a moderated mediation model.

Results: We found that weekly leisure crafting behaviors (ie, seeking structural leisure resources, seeking social leisure resources, seeking leisure challenges, and reducing hindering leisure demands) were positively related to weekly intrinsic need satisfaction (ie, need for competence, autonomy, and relatedness), then resulting in higher weekly subjective well-being (ie, physical thriving, mental health, and life meaningfulness). Moreover, this indirect effect was stronger for those who had a higher level of leisure boredom.

Conclusion: Our study contributes to student development and well-being literature by focusing on the students' leisure context and providing a means to enhance their well-being. We unfold how the leisure crafting strategy boosts college students' well-being via increasing their intrinsic need satisfaction. We also highlight the compensating role of leisure crafting when one is in an unfavorable personal state (eg, leisure boredom).

Keywords: leisure crafting, intrinsic need satisfaction, leisure boredom, college student, well-being, diary study

\section{Introduction}

College students' well-being received increasing attention from both universities and the whole society. ${ }^{1}$ A survey from the World Health Organization shows that $12-46 \%$ of all university students are affected by mental health disorders in any given year. ${ }^{2}$ To facilitate students' well-being, reducing their anxiety and depression, universities and educational managers are taking multidimensional efforts, ranging from study environments to the teacher-student relationship. ${ }^{3-5}$ A report from 400 US university presidents reveals that $87 \%$ of universities took students' well-being as a priority and $72 \%$ of them reallocated and identified additional funding to address students' mental health. ${ }^{6}$ Besides the initiatives of universities, educationalists and psychologists argue that students themselves should actively find ways to increase their subjective well-being. ${ }^{7}$ Studies show that proactive strategies such as self-regulation, ${ }^{8}$ goal-setting, ${ }^{9}$ resilience, ${ }^{10}$ and networking, ${ }^{11}$ are positively related to one's well-being.

While previous studies provided valuable insights into how college students can optimize their study process, and in turn, enhance their well-being, such as increasing perceived academic control, ${ }^{12}$ attaining intrinsic and extrinsic goals, ${ }^{13}$ and engaging in social networking, ${ }^{14}$ we still know relatively little about how college students increase well-being by 
proactively, strategically shaping their leisure context. This might be an omission from the literature because leisure life is important and full of self-growth opportunities and resources. ${ }^{15}$ College students can make optimal use of their leisure lives to recover from study stress, develop new hobbies and life skills, get inspired, and re-gain passion, hope and enthusiasm for life. ${ }^{1,16}$ However, we found that only a small handful of studies investigated the role of leisure activities on college students' well-being, such as sports, reading, and travelling. ${ }^{16-19}$

Therefore, building on limited previous work and the proactivity theory. ${ }^{9}$ In this study, we propose leisure crafting as an efficient strategy to enhance college students' well-being. Based on the resources-demands perspective, ${ }^{20,21}$ leisure crafting is defined as a proactive act whereby individuals balance their leisure resources and demands by utilizing their personal abilities and needs. ${ }^{7}$ Via leisure crafting, college students are able to seek fulfillment and choose and adjust their leisure activities in a manner that addresses their passions and values. ${ }^{22}$ Research shows that leisure crafting is effective in response to high job strain and increases work engagement in the work setting. ${ }^{20,23}$ We expect that the leisure crafting strategy can be applied in the school setting as well to enhance college students' well-being.

To deepen the understanding of the role of leisure crafting, we examine its mediating mechanism and the boundary condition. Following the proactivity and self-determination theories, ${ }^{9,24}$ we aim to shed light on how leisure crafting enhance college students' well-being by increasing their intrinsic psychological needs, and whether leisure crafting is more beneficial and effective for those who have higher leisure boredom perceptions. That said, we examine the mediating role of intrinsic need satisfaction and the moderating role of leisure boredom. Research indicates that intrinsic need satisfaction including the need for autonomy, competence, and relatedness can be activated when one actively shape and take charge of the situations. ${ }^{20,24}$ Also, studies confirm that proactive actions with goal orientation can increase one's energy and alleviate negative psychological states. ${ }^{25}$ Thus, proactive strategies are more effective when one has negative states or meaning-making is threatened. ${ }^{23}$ Therefore, we expect to provide insights into how and when leisure crafting strategy helps college students to improve their well-being.

Moreover, we are interested to unfold a dynamic relationship between leisure crafting and college students' wellbeing. That said, we not only look at how those engaging in leisure crafting (vs those not) resulted in increases in wellbeing (ie, between-person), but also expect to capture how leisure crafting behaviors influence their well-being over time (ie, within-person). This is important because individual behaviors and states are likely to vary across different days/ weeks based on their circumstances, needs, and goals. ${ }^{26}$ Some studies showed that one's current period's behavior can even affect one's next period's behavior and state. ${ }^{26,27}$ Thus, a one-time, cross-sectional investigation cannot capture the "changing" dynamics between leisure crafting behaviors and college students' well-being. Instead, research suggests that a (daily or weekly) diary study can well uncover a short-term dynamic relationship. ${ }^{27}$ Therefore, we conduct a quantitative weekly diary study aiming to reveal the dynamic effects of leisure crafting on students' well-being. By doing so, we expect to understand how leisure crafting is taken as an ongoing action and influences the changes of one's well-being across weeks.

We mainly make the following contributions. First, we add to the student development and well-being literature ${ }^{1,8}$ by proposing leisure crafting as a self-initiated strategy to improve their well-being. Prior studies uncovered the factors of enhancing college students' well-being in the study context, such as goal-oriented self-regulation, study engagement, and resilience. ${ }^{8,10}$ Our study highlights that taking charge and shaping the leisure context is also important and beneficial to students' well-being. College students have ample opportunities to seek more leisure resources and optimize leisure detriments by engaging in leisure crafting strategy. Second, we add to the leisure management literature ${ }^{7,16}$ by highlighting that individuals should more proactively, strategically manage their leisure lives (ie, identifying resources and demands in the leisure context and actively crafting these resources and demands). Therefore, compared to the previous studies uncovering leisure activities such as reading, networking, or physical activities, ${ }^{15,17}$ we point out that leisure crafting is not just a single leisure activity but a series of small meaningful adjustments in the leisure context based on one's own leisure situations, interests, and goals. Based on the "proactive" nature, ${ }^{9}$ we further uncover how leisure crafting leads to a motivational process (ie, the mediating mechanism of intrinsic need satisfaction) and how leisure crafting takes compensating effects when one's psychological resources are threatened (ie, the moderating role of leisure boredom). Third, using a weekly diary design, we shed light on a dynamic relationship between leisure crafting and college students' well-being. Thus, we consider leisure crafting as an ongoing action instead of a one-time event. Consequently, we capture how the changes in leisure crafting 
influence the changes in college students' well-being across weeks. We also increase the causality of the studied relationships using a diary design. This is less conducted from previous leisure management studies. ${ }^{7,28}$ We drew a conceptual model in Figure 1 where we visually indicated the relationships among our studied variables.

\section{Theory and Hypothesis Development \\ Leisure Crafting and College Students' Well-Being}

Well-being is beneficial and important for individuals to live a healthy, meaningful life, making it an essential aspect of one's life in the college years. ${ }^{29}$ Well-being refers to one's positive affect and the perception of life satisfaction. ${ }^{8}$ The well-being literature states that one's well-being is happy-oriented and concerns realizing human potential power. ${ }^{12,23,29}$ Well-being in the college setting mainly includes students' mental, physical health and life meaningfulness. ${ }^{30}$ Research shows that college students' well-being is positively related to personal success, positive states, and selfmotivation. ${ }^{29,31}$ Perceiving a lower level of well-being may result in avoidance behavior, social isolation, sadness, and self-doubt. ${ }^{32}$ Thus, it is important to investigate useful strategies students can take to enhance their well-being. Rather than focusing on the study context, recently, researchers believe that students' leisure context is equally important and full of opportunities and challenges that can enhance one's intrinsic motivation and subjective wellbeing. ${ }^{1,5,8,12,13}$

Focusing on students' leisure context, we propose that leisure crafting could be an efficient strategy increasing wellbeing. Leisure crafting is defined as an active act whereby individuals balance their leisure resources and demands by utilizing their personal abilities and needs. ${ }^{7}$ Following the resources-demands perspective, ${ }^{21}$ leisure resources refer to those aspects in the leisure context that can be functional in achieving goals, or stimulate personal growth, learning, and development, while leisure demands refers to those aspects in the leisure context that require substantial physical and/or psychological effort and drain one's energy. ${ }^{7,21}$ Tsaur et al followed the demands-resources framework ${ }^{21}$ and further proposed four specific leisure crafting behaviors, including seeking structural leisure resources (eg, acquiring relevant knowledge, improving skills and physical strength, or increasing the recreational experience); seeking social leisure resources (eg, acquiring resources provided by others or by leisure companions); seeking leisure challenges (eg, extending their own limits and experiencing novelty and excitement); and reducing leisure barriers (eg, coping with those intrapersonal, interpersonal, and structural constraints such as shyness, undesirable health condition, or skill deficiencies).

Following the proactivity perspective, ${ }^{7,20,23}$ researchers also identify leisure crafting as a kind of proactive behavior whereby people proactively pursue specific goals, human connections, learning, and personal development in leisure activities. Therefore, rather than being spontaneous, leisure crafting is a proactive, goal-focused, and planned behavior characterized by seriousness. ${ }^{33}$ Leisure crafting for the college students resembles family crafting or non-work engagement ${ }^{34}$ but it not only crafts the family domain but the relations with friends, classmates, or even teachers, who brings resources and opportunities for self-growth. Via leisure crafting, students achieve their own fulfillment and shape their leisure activities in a manner that addresses their passions and values. ${ }^{22}$ They can make actual, meaningful adjustments in their leisure time and feel satisfied and happy about the life. Thus:

\section{H1: Leisure crafting is positively related to well-being for college students.}

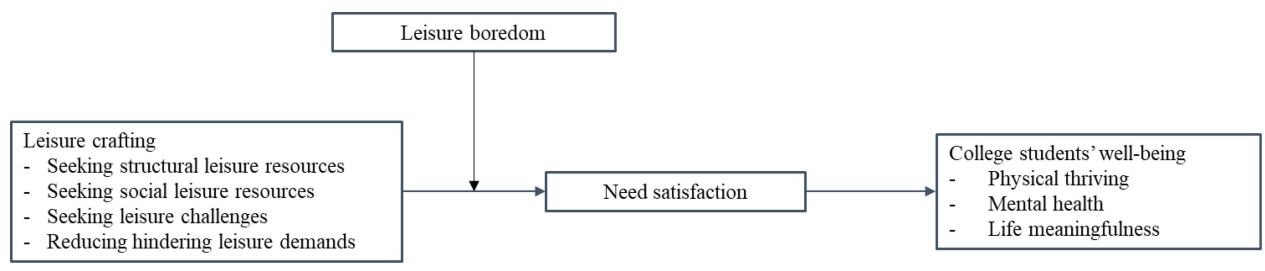

Figure I Conceptual model. 


\section{The Mediating Role of Intrinsic Need Satisfaction}

While the concept of leisure crafting is not new, ${ }^{7,21}$ we still know relatively less about why and how leisure crafting strategy can lead to increased well-being in the college setting. That is, a mediation process behind this relationship is needed to be understood and examined. Based on the proactivity ${ }^{9}$ and self-determination (SDT) ${ }^{24}$ theories, we propose that intrinsic need satisfaction plays a mediating role. The SDT theory posits that the existence of universal psychological needs, that when satisfied, result in optimal functioning and psychological adjustment. ${ }^{24}$ These include the need for autonomy (ie, being the initiator of one's own behavior), competence (ie, succeeding at challenging tasks and desired outcomes), and relatedness (ie, a sense of caring, mutual respect, and mutual reliance with others). ${ }^{24,35}$ The literature uncovers the antecedents of intrinsic need satisfaction. For example, studies show that contextual factors such as autonomy support, job resources can increase need satisfaction. ${ }^{36,37}$ Likewise, behavioral variables such as job crafting, self-regulation can satisfy one's intrinsic needs. ${ }^{8,21}$ Consequently, need satisfaction is positively related to numerous beneficial outcomes such as one's self-growth, fulfillment, and well-being. ${ }^{24,35}$

We argue that leisure crafting is able to satisfy these three needs for college students. First, leisure crafting is a proactive and intentional process, which implies that students take actions towards their goals and take control of their situations, rather than passively accepting situational conditions. ${ }^{20}$ Consequently, via adjusting themselves or the situation, proactive individuals experience the improved future they have envisioned. ${ }^{9}$ Therefore, leisure crafting satisfies the need for autonomy. Second, via leisure crafting (eg, seeking leisure challenges and seeking structural leisure resources), college students try out new things, develop new skills, and achieve a sense of mastery and selfdevelopment. ${ }^{25}$ This will positively link to one's need for competence. Third, via leisure crafting (eg, seeking social leisure resources), college students gain instrumental and emotional support, perceived care and love from their families and friends. This will fulfill the need for relatedness, ie, the need for human connection, loving, and being loved. ${ }^{24}$

Subsequently, we argue that with the satisfaction of three needs, college students' well-being is improved. The SDT theory point out that the extent to which these three needs are satisfied determines the level of one's subjective wellbeing, mental health, and positive affect. ${ }^{24}$ The satisfaction of these needs is associated with hedonic and eudaimonic motives, which is associated with organismic functionality and self-actualization. ${ }^{24}$ The literature also shows that intrinsic need satisfaction is an essential antecedent of thriving in youth ${ }^{38}$ and influences one's vitality. ${ }^{35}$ Extensive evidence suggests that intrinsic need satisfaction is a strong predictor of different well-being indicators such as happiness, life satisfaction, psychological well-being, and subjective well-being (see a review, Van Den Broeck et al 2016). ${ }^{36}$

Taking together, we expect that leisure crafting strategy will first satisfy one's three basic psychological needs (ie, need for autonomy, need for competence, and need for relatedness), which then, makes individuals feel happy, satisfied, and meaningful. Thus:

\section{H2: Intrinsic need satisfaction mediates the relationship between leisure crafting and college students' well-being.}

\section{The Moderating Role of Leisure Boredom}

The previous section expatiates on how leisure crafting facilitates college students' leisure life through increasing their intrinsic need satisfaction. However, we also expect to understand in what circumstances leisure crafting could play a more significant role. In other words, not all individuals may benefit from the leisure crafting strategy equally. Some specific conditions may strengthen/weaken the effect of leisure crafting on people's well-being. Therefore, it is important to gain insights into when students can and should apply leisure crafting strategy, so that they can gain the benefits of engaging in leisure crafting even better. The proactivity literature indicates that proactive behaviors have stronger effects when people face challenging situations or experience difficult times. ${ }^{25,39}$ This is because being proactive enables individuals to act towards their goals and valuable directions, stay at a higher level of energy and motivation, and persist in what they are doing. ${ }^{39}$ For example, prior studies found that employees engaging in job crafting strategy had stronger effects on work attachment when they experience tough times at work. ${ }^{40}$ This is also in line with the conservation of resources theory $(\mathrm{COR})^{41}$ stating that individuals are more willing to take certain actions to protect their current resources or acquire new resources when their current (psychological, physical) resources are lost or threatened. Thus, we argue that leisure crafting, as a form of proactive behavior aiming to adjust resources and demands 
in the leisure context, could have stronger effects when one is in an unfavorable situation or his/her (psychological, physical) resources are threatened.

Following this reasoning, we consider a typical situation for college students: leisure boredom. An investigation on the quality of leisure time in 36 countries showed that approximately $68 \%$ of individuals indicated they experienced boredom in their leisure time. ${ }^{42}$ The boredom level of students in leisure time is even higher than the boredom level of people in other occupational groups. ${ }^{43}$ Leisure boredom refers to the perceived status that available leisure experiences are insufficient to instrumentally satisfy needs for optimal arousal. ${ }^{44}$ Research shows that leisure boredom is a negative state, such as perceived meaningless and dissatisfaction, ${ }^{28}$ and could lead to unexpected consequences, such as internet addiction, excessive drinking, or other risky behaviors. ${ }^{45}$

We argue that leisure crafting is more beneficial and helpful for those who experience a higher level of leisure boredom. That said, leisure crafting is a very promising strategy to offset the negative impact of leisure boredom. Based on the proactivity ${ }^{9}$ and the conservation of resources ${ }^{41}$ perspectives, leisure crafting involves a proactive process aimed at increasing leisure resources and decreasing leisure detriments. This process satisfies one's basic needs, increases positive affect and vitality. ${ }^{23}$ Research shows that individuals will feel less bored when they have enjoyable things to do and have excellent leisure management skills. ${ }^{46}$ Therefore, for those college students who feel bored in the leisure time, we argue that the leisure crafting strategy (eg, seeking leisure resources, seeking leisure challenges) is an effective leisure management strategy to alleviate the boredom state. Via leisure crafting (eg, increasing leisure resources and challenging demands), students could customize the leisure activities based on their own needs, goals, and preferences; and obtain a higher level of energy, excitement, and meaningfulness. ${ }^{7,20}$ This process could efficiently buffer the negative personal states, such as boredom, uninterestedness, or hopelessness. ${ }^{7,33}$ Prior studies found that leisure crafting was an efficient compensating strategy when individuals were in a highly stressful state, ${ }^{20}$ or when meaning-making was threatened. ${ }^{23}$ Wang et al pointed out that free-time management with goal-oriented and scheduling was effective in alleviating the negative impact of boredom. Thus:

H3: The beneficial role of leisure crafting on college students' well-being via intrinsic need satisfaction becomes stronger for those college students who have a higher level of leisure boredom (vs lower).

\section{Methods}

\section{Sample and Participants}

The quantitative diary study design is widely used in recent management and psychology studies. ${ }^{27}$ The quantitative diary study is considered as a way of collecting data in repeated times (on a daily or weekly level). Participants filled in the survey once a week or a day, which looks like that they fill in a "diary" to record their thoughts, feelings, and behaviors. However, this is not a normal diary that people need to write down some words or sentences but a more "structural" diary that researchers provide several relevant questions to ask participants to self-reflect upon what they think, feel, and behave within a day or a week. In essence, a quantitative diary study is a short-term longitudinal study. Thus, a quantitative diary study is particularly used for capturing daily/weekly fluctuations in terms of one's states, moods, behaviors, and performance. ${ }^{27}$ Scholars increasingly acknowledge that the diary study is beneficial because it can capture "life as it is lived". ${ }^{47}$ For example, individuals" emotions, behaviors, and/or performance are very likely to change across different days/weeks based on various internal and external factors and conditions. ${ }^{26}$ The current states and behaviors may influence next period's (eg, next day/week) states and performance. The traditional cross-sectional study cannot uncover this "changing" phenomenon. Thus, apart from showing relationships between individuals, a diary study can capture the short-term dynamics of one's states and behaviors over time within individuals. ${ }^{27}$ Research also shows that the diary design can reduce possible retrospective bias and increase the likelihood of causality for the studied relationships since it includes repeated measures. ${ }^{26,27}$ Thus, in this study, conducting a weekly diary study, we not only looked at how those engaging in leisure crafting (vs those not) resulted in increases in well-being (ie, between-person), but also aimed to capture how leisure crafting behaviors influence their well-being over time (ie, within-person).

Our weekly diary design includes two parts: a general questionnaire at the beginning and four weekly diaries afterward. In the general questionnaire, we briefly welcomed participants to attend the study. We explained to our 
participants that this study was to record the fluctuations of their behaviors and states over four weeks, and there was no right or wrong answer (ie, we intentionally hide the real research question to reduce common method bias). The confidentiality and anonymity of responses were also protected. In the general questionnaire, we asked participants to fill in their basic demographic information such as age and gender and create a unique identification code, which will be used to match the following weekly diaries. Subsequently, we sent the diary questionnaires once a week for four consecutive weeks. In each weekly diary questionnaire, participants were asked to fill in their ratings about their leisure crafting behaviors, need satisfaction, leisure boredom perceptions, and well-being in the current week. We sent it every Friday and expected participants to complete it by the end of Sunday. During this stage, except that we had an automatic email reminder for participants filling in the diary questionnaire, we did not have any verbal or non-verbal interactions with the participants. In addition, to control the order effects in the survey design, we used separate pages to divide each questionnaire scale to avoid participants looking back at their ratings.

To reduce potential participants' biases and ensure that our analyses have adequate statistical power, we conducted a power analysis before recruiting the participants. The power analysis results showed that at least 36 individuals with four-time repeated measures are required if statistical power is expected to be above $95 \%$. Besides, Gabriel et al reviewed 90 diary studies in management and psychology fields and concluded that the sample size was 83 on average in those diary studies, and they recommended that a diary study should have at least 83 . Therefore, to ensure that we have adequate statistical power, we decided to recruit at least 90 participants in this weekly diary study. We sent the invitation link to an engineering college in China. The second author contacted and communicated this engineering college for cooperation. The participants were from their third college year. We sent the invitation to 332 students in total. However, only 89 students indicated they were willing to participate in this survey. Thus, we only sent the following diary surveys to these 89 students. However, we excluded 9 participants because they only filled in one weekly diary questionnaire, which is insufficient to examine the dynamic fluctuations over time. Finally, we obtained 80 out of 89 participants (ie, 320 data points in total) who filled in both a general questionnaire and four weekly questionnaires. The response rate was $89.89 \%$. The participants' average age was $22.43(\mathrm{SD}=0.82) .83 .1 \%$ of our sample was male, while $16.9 \%$ were female.

\section{Measures}

The questionnaires were administered in the Chinese language and scales were translated into Chinese and back translated into English to ensure consistency. We adjusted the items to fit in the week-level context. Unless otherwise stated, all measures used a 5-point Likert scale $(1=$ strongly disagree, $5=$ strongly agree $)$.

Weekly leisure crafting was assessed with 15 items developed by Tsaur et al. ${ }^{7}$ We identified four specific leisure crafting strategies: (1) weekly seeking structural leisure resources ("This week, I strived to develop knowledge related to target leisure activities" 5 items; Cronbach's $\alpha=0.86,0.89,0.87,0.84$ at T1, T2, T3, T4); (2) weekly seeking social leisure resources ("This week, I actively built good relationships with my leisure companions" 3 items; $\alpha=0.81,0.83$, 0.76, 0.85 at T1, T2, T3, T4); (3) weekly seeking leisure challenges ("This week, I expanded or adjusted the scope of leisure participation to make it more challenging" 3 items, $\alpha=0.88,0.85,0.72,0.83$ at T1, T2, T3, T4); and (4) weekly reducing hindering leisure demands ("This week, I chose those leisure activities that well match my interests and abilities" 4 items, $\alpha=0.85,0.88,0.87,0.84$ at T1, T2, T3, T4).

Weekly need satisfaction was assessed with 9 items used by Petrou et al. ${ }^{20}$ The example item is "This week, I felt that my choices were based on my true interests and values during the leisure activities" (need for autonomy); "This week, I felt very capable in what I did during the leisure activities" (need for competence); "This week, I felt a strong sense of intimacy with the people I spent time with in a leisure activity" (need for relatedness). Cronbach's $\alpha=0.90,0.91,0.84$, 0.91 at $\mathrm{T} 1, \mathrm{~T} 2, \mathrm{~T} 3, \mathrm{~T} 4$.

Weekly leisure boredom was assessed with 4 items developed by Iso-Ahola et al. ${ }^{44} \mathrm{An}$ example item is "This week, my leisure time is boring". Cronbach's $\alpha=0.82,0.83,0.72,0.90$ at T1, T2, T3, T4.

Weekly well-being was assessed with 6 items for mental health and physical thriving developed by Sheldon et al ${ }^{48}$ and 3 items for life meaningfulness developed by Steger et al. ${ }^{49}$ An example item for physical thriving is "This week, I felt that I got enough exercise and was in good physical condition". Cronbach's $\alpha=0.84,0.84,0.75,0.82$ at T1, T2, T3, T4. An example item for mental health is "This week, I am often carefree and in good spirits". Cronbach's $\alpha=0.89,0.79$, 
$0.82,0.74$ at T1, T2, T3, T4. An example item for life meaningfulness is "This week, I have a good sense of what makes my life meaningful”. Cronbach's $\alpha=0.86,0.88,0.78,0.82$ at T1, T2, T3, T4.

\section{Control Variables}

Following previous crafting studies, ${ }^{20,50}$ we considered age and gender as controls as individuals with different genders and ages may have different levels of crafting behaviors. Besides, to strengthen the causality and overcome potential endogeneity, endogeneity refers to a measurement bias that a predictor correlates with the unexplained residual of the outcome in a statistical model. It may result from four sources: omitted variable, simultaneity, measurement error, and selection (of treatment and/or into sample). Therefore, in the social science including psychology field, we cannot fully avoid endogeneity, but we can attempt to control it. One of the simplest ways is to add control variables or the lagged terms into the statistical model to decrease possible omitted variables and increase causality, which was in line with suggestions, ${ }^{47}$ we also controlled for the lagged term (ie, t-1 period) of the dependent variables and independent variables (ie, the t-1 period of physical thriving, mental health, and life meaningfulness, and t-1 period of leisure crafting and intrinsic need satisfaction).

\section{Analytical Approach}

Owing to the nested structure of our data (weeks nested in persons), we applied multilevel analyses to test our proposed hypotheses. To determine whether multilevel analysis was appropriate, we first calculated the intra-class correlation (ICC). The ICC reports on the amount of variation unexplained by any predictors in the model that can be attributed to the grouping variable, as compared to the overall unexplained variance (within and between variance). Our results showed that our level 1 (week-level) variables: seeking structural leisure resources (34.31\%), seeking social leisure resources $(41.66 \%)$, seeking leisure challenges (36.88\%), reducing hindering leisure demands $(37.13 \%)$, need satisfaction (49.31\%), leisure boredom (49.86\%), physical thriving (48.56\%), mental health (47.21\%), and life meaningfulness (54.13\%). These results supported the use of multilevel analysis. This implies that students not only scored differently for the studied variables but also showed variances of the studied variables over time within each student.

We used MLwiN software to perform multilevel regressions. The steps are as follows: first, we entered intercept and control variables. Second, we entered the predictors (ie, four leisure crafting behaviors) separately. We examined the random effects of slopes and tested the improvement of each model over the previous one by computing the differences of their $\log$-likelihood statistic $-2 * \log$ and subjected this difference to a $\chi^{2}$ significance test. Notably, all week-level variables were person-mean centered in order to avoid multicollinearity and spurious regression.

To examine the mediation and moderated mediation effects, we used MLmed Macro. ${ }^{51}$ This procedure can calculate 95\% Monte Carlo confidence intervals based on 10,000 bootstrapping for the multilevel mediation effects and the multilevel moderated mediation effects. As our data were nested in two levels, MLmed Macro is an appropriate tool to conduct such analyses, compared to the traditional PROCESS Macro, which cannot examine the multilevel data.

\section{Results}

\section{Preliminary Analysis}

Table 1 shows means, standard deviations, and correlations among all the study variables. Since we had multilevel data structure, we reported not only variables' correlations on the between-person level, but also correlations on the withinperson level. Table 1 shows that gender was not related to any of our studied variables (on the person-level), which implied that gender did not influence leisure crafting behavior, need satisfaction, and well-being. We found that age was negatively related to two dimensions of leisure crafting - seeking structural leisure resources $(r=-0.09, p<0.05)$ and reducing hindering leisure demands $(r=-0.13, p<0.01)$, and that age was negatively related to need satisfaction $(r=$ $-0.11, p<0.01)$. This implied that the older individuals, on general, had the lower level of leisure crafting behaviors and the lower level of need satisfaction.

Before testing our hypotheses, we ran multilevel confirmatory factor analysis (CFA) to explore the factorial structures of our measures using Mplus software. The analysis type is TWOLEVEL. The results of multilevel CFA are shown in 
Table I Means, S.D., and Between-Person Level (Below the Diagonal) and Within-Person Level (Above the Diagonal) Correlations Among the Study Variables

\begin{tabular}{|c|c|c|c|c|c|c|c|c|c|c|c|c|c|}
\hline & Mean & S.D. & $\mathbf{I}$ & 2 & 3 & 4 & 5 & 6 & 7 & 8 & 9 & 10 & II \\
\hline I. Age & 22.43 & 0.82 & & -0.01 & -0.08 & -0.04 & -0.06 & $-0.14 * *$ & $-0.11 *$ & 0.07 & -0.02 & -0.08 & $-0.13 * *$ \\
\hline 2. Gender & 1.17 & 0.38 & -0.01 & & -0.03 & -0.07 & $-0.11 *$ & $-0.12^{* *}$ & $-0.13^{* *}$ & $0.11 *$ & $-0.09 *$ & -0.08 & -0.02 \\
\hline 3. Seeking structural leisure resources & 3.94 & 0.65 & $-0.09 *$ & -0.02 & & $0.7 \mathrm{I} * *$ & $0.69 * *$ & $0.6 I^{* *}$ & $0.63 * *$ & $-0.58 * *$ & $0.53 * *$ & $0.61 * *$ & $0.58 * *$ \\
\hline 4. Seeking social leisure resources & 3.95 & 0.68 & -0.05 & -0.04 & $0.66 * *$ & & $0.66 * *$ & $0.69 * *$ & $0.61 * *$ & $-0.52^{* *}$ & $0.44 * *$ & $0.61 * *$ & $0.52 * *$ \\
\hline 5. Seeking leisure challenges & 3.84 & 0.75 & -0.08 & -0.08 & $0.6 \mathrm{I}^{* *}$ & $0.60 * *$ & & $0.65 * *$ & $0.60 * *$ & $-0.55^{* *}$ & $0.56 * *$ & $0.56 * *$ & $0.54 * *$ \\
\hline 6. Reducing hindering leisure demands & 3.99 & 0.65 & $-0.13^{* *}$ & -0.07 & $0.52 * *$ & $0.58 * *$ & $0.59 * *$ & & $0.70 * *$ & $-0.53^{* *}$ & $0.48 * *$ & $0.62 * *$ & $0.59 * *$ \\
\hline 7. Need satisfaction & 3.97 & 0.56 & $-0.11^{*}$ & -0.08 & $0.57^{* *}$ & $0.57 * *$ & $0.56 * *$ & $0.61 * *$ & & $-0.62^{* *}$ & $0.51 * *$ & $0.66 * *$ & $0.64 * *$ \\
\hline 8. Leisure boredom & 3.05 & 0.61 & 0.06 & 0.08 & $-0.45 * *$ & $-0.47^{* *}$ & $-0.49 * *$ & $-0.45^{* *}$ & $-0.55^{* *}$ & & $-0.59 * *$ & $-0.69 * *$ & $-0.68 * *$ \\
\hline 9. Physical thriving & 3.94 & 0.69 & -0.01 & -0.05 & $0.47^{* *}$ & $0.46 * *$ & $0.50 * *$ & $0.46 * *$ & $0.5 \mathrm{I} * *$ & $-0.58^{* *}$ & & $0.57 * *$ & $0.55 * *$ \\
\hline 10. Mental health & 4.02 & 0.63 & -0.09 & -0.05 & $0.49 * *$ & $0.53 * *$ & $0.46 * *$ & $0.54 * *$ & $0.61 * *$ & $-0.59 * *$ & $0.59 * *$ & & $0.61 * *$ \\
\hline II. Life meaningfulness & 4.89 & 0.74 & -0.11 & -0.01 & $0.49 * *$ & $0.47^{* *}$ & $0.48 * *$ & $0.50 * *$ & $0.59 * *$ & $-0.60^{* *}$ & $0.55 * *$ & $0.58 * *$ & \\
\hline
\end{tabular}

Notes: $\mathrm{N}=89$ participants and $\mathrm{N}=320$ data points; ${ }^{*} p<0.01 ;{ }^{*} p<0.05 ;$ gender $($ male $=1$; female $=2$ ). 
Table 2, indicating that the measurement model distinguishing 9 constructs (ie, four leisure crafting behaviors + leisure boredom + need satisfaction +3 well-being dimension including physical thriving, mental health, life meaningfulness) showed the best fitting indices: $\chi^{2}=1889.496 ; d f=1159$; CFI $=0.897$; TLI $=0.881$; SRMR within $=0.045$; SRMR between $=0.143$; RMSEA $=0.044$. This model was significantly better than the model collapsing four leisure crafting behaviors into one factor $\left(\chi^{2}=2314.991 ; d f=1205 ; \mathrm{CFI}=0.843\right.$; TLI $=0.827$; SRMR within $=0.071$; SRMR between $=$ 0.128 ; RMSEA $\left.=0.054 ; \Delta \chi^{2}(46)=425.495, p<0.001\right)$. Notably, the cutoff values are: CFI $>0.90$; TLI $>0.90 ;$ SRMR $<$ 0.08 ; RMSEA $<0.08$. As we focused more on the within-person variance in a weekly diary design, the values of the SRMR between can be ignored. This model was also significantly better than the model collapsing three well-being dimensions into one factor $\left(\chi^{2}=2189.199 ; d f=1190 ; \mathrm{CFI}=0.859\right.$; TLI $=0.842$; SRMR within $=0.056$; SRMR between $=0.148 ;$ RMSEA $\left.=0.051 ; \Delta \chi^{2}(31)=299.703, p<0.001\right)$. To conclude, the results demonstrated that the 9-factors model had better fit than alternative models, supporting the discriminant validity.

\section{Hypothesis Testing}

Table 3 shows that seeking structural leisure resources was positively related to physical thriving $(b=0.13, p<0.05)$, mental health $(b=0.14, p<0.05)$, and life meaningfulness $(b=0.16, p<0.05)$; seeking social leisure resources was positively related to physical thriving $(b=0.14, p<0.05)$, mental health $(b=0.15, p<0.05)$, and life meaningfulness ( $b=0.14, p<0.05$ ); seeking leisure challenges was positively related to physical thriving $(b=0.17, p<0.01)$, mental health $(b=0.18, p<0.05)$, and life meaningfulness $(b=0.16, p<0.001)$; reducing hindering leisure demands was positively related to physical thriving ( $b=0.26, p<0.05)$, mental health $(b=0.29, p<0.001)$, and life meaningfulness $(b=0.29, p<0.001)$. Therefore, hypothesis 1 was supported.

MLmed results (Table 4) showed that except the indirect effect of weekly reducing hindering leisure demands on weekly physical thriving through weekly need satisfaction $(b=0.046,[-0.067,0.162])$, all the indirect effects were significant without including zero in the confidence intervals. The detailed indirect effects could be found in Table 4 . Therefore, hypothesis 2 was generally supported.

To test the moderated mediation effect, we first examined the two-way interaction terms between leisure crafting and leisure boredom. The results showed significant two-way interaction terms between weekly seeking social leisure resources and weekly leisure boredom $(b=0.41, p<0.01)$, and between weekly seeking leisure challenges and weekly leisure boredom $(b=0.25, p<.05)$. We also conducted the simple slope test. The results indicated that weekly seeking social leisure resources was positively related to weekly need satisfaction $(b=0.33 ; p=0.014)$ when weekly leisure boredom was high, but it is insignificant when weekly leisure boredom was low ( $b=-0.17 ; p=0.017$ ) (see Figure 2); weekly seeking leisure challenges was positively related to weekly need satisfaction when weekly leisure boredom was high $(b=0.32 ; p=0.003)$, while it is insignificant when weekly leisure boredom was low $(b=0.02 ; p=0.83)$ (see Figure 3).

We also used MLmed Macro to calculate the index of moderated mediation to get an integrative moderated mediation model. Table 4 shows the similar results: the moderated mediation effects of seeking social leisure resources on physical thriving, mental health, and life meaningfulness were 0.098 [0.011, 0.220], $0.171[0.062,3.310]$, and 0.154 [0.054, 0.284], respectively; the moderated mediation effects of seeking leisure challenges on physical thriving, mental health, and life meaningfulness were 0.052 [0.004, 0.132], 0.086 [0.014, 0.183], and 0.090 [0.012, 0.189], respectively. Hence, hypothesis 3 was supported for weekly seeking social leisure resources and weekly seeking leisure challenges. Finally, we present our results in one integrated diagram. However, due to the page limit, we put it in Figure A.

\section{Discussion}

Grounded in the proactive behavior ${ }^{9}$ and SDT $^{24}$ theories, this study sheds light on how and when college students could engage in leisure crafting strategy to enhance their well-being. Conducting a weekly diary study, we found that leisure crafting behaviors (ie, seeking structural leisure resources, seeking social leisure resources, seeking leisure challenges, and reducing leisure hindering demands) increased students' intrinsic need satisfaction on a weekly basis, and consequently, enhanced their well-being across weeks. Moreover, this indirect effect was stronger for those who had a higher level of leisure boredom. Finally, we found that gender did not impact the level of leisure crafting, need satisfaction, and 
Table 2 Fit Indices of Alternative Measurement Models

\begin{tabular}{|c|c|c|c|c|c|c|c|c|c|}
\hline Model & $\chi^{2}$ & df & CFI & TLI & RMSEA & SRMR Within & SRMR Between & Model Comparison & $\Delta \chi^{2}(\mathrm{df})$ \\
\hline MI: 9 factors (best fitting model) & 1889.496 & 1159 & 0.897 & 0.881 & 0.044 & 0.045 & 0.143 & - & - \\
\hline M2: 7 factors & 2189.199 & 1190 & 0.859 & 0.842 & 0.051 & 0.056 & 0.148 & $M 1$ vs $M 2$ & $299.703(3 \mathrm{I})^{* * *}$ \\
\hline M3: 6 factors & $23|4.99|$ & 1205 & 0.843 & 0.827 & 0.054 & 0.071 & 0.128 & MI vs $M 3$ & $425.495(46) * * *$ \\
\hline M4: 4 factors & 2531.916 & 1224 & 0.815 & 0.799 & 0.058 & 0.088 & 0.192 & MI vs M4 & $642.420(65)^{* * *}$ \\
\hline M5: II factors & 1850.969 & $|12|$ & 0.897 & 0.877 & 0.045 & 0.044 & 0.137 & MI vs M5 & 38.527 (38) \\
\hline
\end{tabular}

Notes: $* * *$ p $<0.001$; MI: four leisure crafting dimensions + leisure boredom + need satisfaction + physical thriving + mental health + life meaningfulness; M2: four leisure crafting dimensions + leisure boredom + need satisfaction + physical thriving, mental health, and life meaningfulness as one factor; M3: four leisure crafting dimensions as one factor + leisure boredom + need satisfaction + physical thriving + mental health + life meaningfulness; M4: our leisure crafting dimensions as one factor + leisure boredom + need satisfaction + physical thriving, mental health, and life meaningfulness as one factor; M5: four leisure crafting dimensions + leisure boredom + three need satisfaction dimensions + physical thriving + mental health + life meaningfulness. However, M5 is not significantly different from MI. Thus, we still choose MI as the best fitting measurement model. 
Table 3 Multilevel Regression Results of Leisure Crafting Predicting Well-Being

\begin{tabular}{|c|c|c|c|c|c|c|c|c|c|c|c|c|}
\hline & \multicolumn{4}{|c|}{ Physical Thriving } & \multicolumn{4}{|c|}{ Mental Health } & \multicolumn{4}{|c|}{ Life Meaningfulness } \\
\hline & Model I & Model 2 & Model 3 & Model 4 & Model 5 & Model 6 & Model 7 & Model 8 & Model 9 & Model 10 & Model II & Model 12 \\
\hline Constant & $\begin{array}{l}3.14 \\
(1.64)\end{array}$ & $\begin{array}{l}3.50 * \\
(1.64)\end{array}$ & $\begin{array}{l}3.27 \\
(1.66)\end{array}$ & $\begin{array}{l}3.55^{*} \\
(1.65)\end{array}$ & $\begin{array}{l}6.51 * * * \\
(1.54)\end{array}$ & $\begin{array}{l}6.37 * * * \\
(1.53)\end{array}$ & $\begin{array}{l}6.19 * * * \\
(1.52)\end{array}$ & $\begin{array}{l}6.41^{* * * *} \\
(1.52)\end{array}$ & $\begin{array}{l}6.55 * * * \\
(1.79)\end{array}$ & $\begin{array}{l}6.51^{* * * *} \\
(1.80)\end{array}$ & $\begin{array}{l}6.89 * * * \\
(1.82)\end{array}$ & $\begin{array}{l}6.17^{* * *} \\
(1.81)\end{array}$ \\
\hline Age & $\begin{array}{l}0.03 \\
(0.07)\end{array}$ & $\begin{array}{l}0.02 \\
(0.07)\end{array}$ & $\begin{array}{l}0.03 \\
(0.07)\end{array}$ & $\begin{array}{l}0.02 \\
(0.07)\end{array}$ & $\begin{array}{l}-0.10 \\
(0.07)\end{array}$ & $\begin{array}{l}-0.10 \\
(0.07)\end{array}$ & $\begin{array}{l}-0.09 \\
(0.07)\end{array}$ & $\begin{array}{l}-0.10 \\
(0.07)\end{array}$ & $\begin{array}{l}-0.09 \\
(0.08)\end{array}$ & $\begin{array}{l}-0.09 \\
(0.08)\end{array}$ & $\begin{array}{l}-0.09 \\
(0.08)\end{array}$ & $\begin{array}{l}-0.10 \\
(0.08)\end{array}$ \\
\hline Gender & $\begin{array}{l}-0.06 \\
(0.15)\end{array}$ & $\begin{array}{l}-0.06 \\
(0.15)\end{array}$ & $\begin{array}{l}-0.07 \\
(0.16)\end{array}$ & $\begin{array}{l}-0.07 \\
(0.16)\end{array}$ & $\begin{array}{l}-0.06 \\
(0.14)\end{array}$ & $\begin{array}{l}-0.07 \\
(0.14)\end{array}$ & $\begin{array}{l}-0.07 \\
(0.14)\end{array}$ & $\begin{array}{l}-0.08 \\
(0.14)\end{array}$ & $\begin{array}{l}0.02 \\
(0.17)\end{array}$ & $\begin{array}{l}0.02 \\
(0.17)\end{array}$ & $\begin{array}{l}0.01 \\
(0.17)\end{array}$ & $\begin{array}{l}0.01 \\
(0.17)\end{array}$ \\
\hline Physical thriving (lag) & $\begin{array}{l}-0.28^{* * * *} \\
(0.07)\end{array}$ & $\begin{array}{l}-0.22^{* *} \\
(0.07)\end{array}$ & $\begin{array}{l}-0.24^{* * *} \\
(0.06)\end{array}$ & $\begin{array}{l}-0.22^{* *} \\
(0.06)\end{array}$ & & & & & & & & \\
\hline Mental health (lag) & & & & & $\begin{array}{l}-0.36^{* * * *} \\
(0.08)\end{array}$ & $\begin{array}{l}-0.24 * * \\
(0.07)\end{array}$ & $\begin{array}{l}-0.26 * * \\
(0.07)\end{array}$ & $\begin{array}{l}-0.30 * * * \\
(0.07)\end{array}$ & & & & \\
\hline Life meaningfulness (lag) & & & & & & & & & $\begin{array}{l}-0.15 * * \\
(0.07)\end{array}$ & $\begin{array}{l}-0.14^{*} \\
(0.06)\end{array}$ & $\begin{array}{l}-0.15^{\text {*** }} \\
(0.06)\end{array}$ & $\begin{array}{l}-0.16^{*} \\
(0.06)\end{array}$ \\
\hline Seeking structural leisure resources (lag) & $\begin{array}{l}0.12 \\
(0.07)\end{array}$ & & & & $\begin{array}{l}0.01 \\
(0.06)\end{array}$ & & & & $\begin{array}{l}-0.01 \\
(0.06)\end{array}$ & & & \\
\hline Seeking social leisure resources (lag) & & $\begin{array}{l}0.12 \\
(0.07)\end{array}$ & & & & $\begin{array}{l}0.06 \\
(0.06)\end{array}$ & & & & $\begin{array}{l}-0.04 \\
(0.06)\end{array}$ & & \\
\hline Seeking leisure challenges (lag) & & & $\begin{array}{l}0.19 * * * \\
(0.06)\end{array}$ & & & & $\begin{array}{l}0.11 \\
(0.06)\end{array}$ & & & & $\begin{array}{l}0.07 \\
(0.06)\end{array}$ & \\
\hline Reducing hindering leisure demands (lag) & & & & $\begin{array}{l}0.16 \text { ** } \\
(0.07)\end{array}$ & & & & $\begin{array}{l}0.20 \text { ** } \\
(0.07)\end{array}$ & & & & $\begin{array}{l}0.09 \\
(0.07)\end{array}$ \\
\hline Seeking structural leisure resources & $\begin{array}{l}0.13^{*} \\
(0.06)\end{array}$ & & & & $\begin{array}{l}0.14^{*} \\
(0.06)\end{array}$ & & & & $\begin{array}{l}0.16^{*} \\
(0.06)\end{array}$ & & & \\
\hline Seeking social leisure resources & & $\begin{array}{l}0.14^{*} \\
(0.07)\end{array}$ & & & & $\begin{array}{l}0.15^{*} \\
(0.07)\end{array}$ & & & & $\begin{array}{l}0.14^{*} \\
(0.06)\end{array}$ & & \\
\hline Seeking leisure challenges & & & $\begin{array}{l}0.17 \text { ** } \\
(0.06)\end{array}$ & & & & $\begin{array}{l}0.18^{*} \\
(0.06)\end{array}$ & & & & $\begin{array}{l}0.16^{*} \\
(0.06)\end{array}$ & \\
\hline Reducing hindering leisure demands & & & & $\begin{array}{l}0.26 \text { **** } \\
(0.07)\end{array}$ & & & & $\begin{array}{l}0.29 * * * * \\
(0.06)\end{array}$ & & & & $\begin{array}{l}0.29 * * * * \\
(0.06)\end{array}$ \\
\hline Level 2 variance & $0.22(0.04)$ & $0.22(0.05)$ & $0.23(0.05)$ & $0.23(0.05)$ & $0.20(0.04)$ & $0.19(0.04)$ & $0.19(0.04)$ & $0.19(0.04)$ & $0.29(0.05)$ & $0.29(0.05)$ & $0.30(0.06)$ & $0.30(0.05)$ \\
\hline Level I variance & $0.15(0.02)$ & $0.16(0.02)$ & $0.15(0.02)$ & $0.15(0.02)$ & $0.13(0.02)$ & $0.15(0.02)$ & $0.14(0.02)$ & $0.13(0.02)$ & $0.13(0.02)$ & $0.13(0.02)$ & $0.13(0.02)$ & $0.12(0.02)$ \\
\hline$-2 \mathrm{LL}$ & 343.00 & 354.55 & 345.93 & 345.77 & 314.91 & 327.63 & 321.66 & 311.52 & 330.71 & 332.52 & 343.30 & 330.00 \\
\hline
\end{tabular}

Notes: $\mathrm{N}=89$ participants and $\mathrm{N}=320$ data points. $* * * \mathrm{p}<0.00 \mathrm{I} ; * \mathrm{*} p<.01$; $* \mathrm{p}<0.05$. "lag" refers to the lagged term. The standard error is reported in the brackets. 
Table 4 MLmed Results for the Mediation Effects and Moderated Mediation Effects on the Within-Person Level

\begin{tabular}{|c|c|c|c|c|c|c|}
\hline Control for Age, Gender, and the Corresponding Lagged Variables & Estimate & se & z-Statistics & $\mathbf{p}$ & LL & UL \\
\hline Weekly seeking structural leisure resources $\rightarrow>$ weekly need satisfaction $\rightarrow>$ weekly physical thriving & 0.076 & 0.035 & 2.179 & 0.029 & 0.012 & 0.149 \\
\hline Weekly seeking structural leisure resources $\rightarrow>$ weekly need satisfaction $\rightarrow>$ weekly mental health & 0.129 & 0.035 & 3.661 & 0.003 & 0.068 & 0.205 \\
\hline Weekly seeking structural leisure resources $\rightarrow>$ weekly need satisfaction $\rightarrow>$ weekly life meaningfulness & 0.107 & 0.033 & 3.254 & 0.001 & 0.049 & 0.177 \\
\hline Weekly seeking social leisure resources -> weekly need satisfaction -> weekly physical thriving & 0.051 & 0.027 & 1.889 & 0.059 & 0.005 & 0.111 \\
\hline Weekly seeking social leisure resources $\rightarrow>$ weekly need satisfaction $\rightarrow>$ weekly mental health & 0.089 & 0.030 & 2.952 & 0.003 & 0.037 & 0.154 \\
\hline Weekly seeking social leisure resources $\rightarrow>$ weekly need satisfaction $\rightarrow>$ weekly life meaningfulness & 0.076 & 0.028 & 2.721 & 0.007 & 0.029 & 0.137 \\
\hline Weekly seeking leisure challenges $\rightarrow>$ weekly need satisfaction $\rightarrow>$ weekly physical thriving & 0.067 & 0.033 & 2.009 & 0.045 & 0.006 & 1.367 \\
\hline Weekly seeking leisure challenges $\rightarrow>$ weekly need satisfaction $\rightarrow>$ weekly mental health & 0.109 & 0.033 & 3.307 & 0.001 & 0.051 & 0.180 \\
\hline Weekly seeking leisure challenges $\rightarrow>$ weekly need satisfaction $\rightarrow>$ weekly life meaningfulness & 0.107 & 0.033 & 3.237 & 0.001 & 0.048 & 0.177 \\
\hline Weekly reducing hindering leisure demands $\rightarrow>$ weekly need satisfaction $\rightarrow$ weekly physical thriving & 0.046 & 0.058 & 0.794 & 0.427 & -0.07 & 0.162 \\
\hline Weekly reducing hindering leisure demands $\rightarrow>$ weekly need satisfaction $\rightarrow>$ weekly mental health & 0.155 & 0.053 & 2.938 & 0.003 & 0.056 & 0.261 \\
\hline Weekly reducing hindering leisure demands $\rightarrow>$ weekly need satisfaction $\rightarrow>$ weekly life meaningfulness & 0.106 & 0.052 & 2.039 & 0.041 & 0.004 & 0.207 \\
\hline Predictor & \multicolumn{2}{|l|}{ Outcome } & \multicolumn{2}{|c|}{$\begin{array}{l}\text { Index of moderated } \\
\text { mediation }\end{array}$} & LL & UL \\
\hline Weekly seeking structural leisure resources & \multicolumn{2}{|c|}{ Weekly physical thriving } & \multicolumn{2}{|c|}{0.002} & -0.052 & 0.056 \\
\hline Weekly seeking structural leisure resources & \multicolumn{2}{|c|}{ Weekly mental health } & \multicolumn{2}{|c|}{0.059} & -0.054 & 0.184 \\
\hline Weekly seeking structural leisure resources & \multicolumn{2}{|c|}{ Weekly life meaningfulness } & \multicolumn{2}{|c|}{0.046} & -0.046 & 0.149 \\
\hline Weekly seeking social leisure resources & \multicolumn{2}{|c|}{ Weekly physical thriving } & \multicolumn{2}{|c|}{0.098} & 0.011 & 0.220 \\
\hline Weekly seeking social leisure resources & \multicolumn{2}{|c|}{ Weekly mental health } & \multicolumn{2}{|c|}{0.171} & 0.062 & 3.310 \\
\hline Weekly seeking social leisure resources & \multicolumn{2}{|c|}{ Weekly life meaningfulness } & \multicolumn{2}{|c|}{0.154} & 0.054 & 0.284 \\
\hline Weekly seeking leisure challenges & \multicolumn{2}{|c|}{ Weekly physical thriving } & \multicolumn{2}{|c|}{0.052} & 0.004 & 0.132 \\
\hline Weekly seeking leisure challenges & \multicolumn{2}{|c|}{ Weekly mental health } & \multicolumn{2}{|c|}{0.086} & 0.014 & 0.183 \\
\hline Weekly seeking leisure challenges & \multicolumn{2}{|c|}{ Weekly life meaningfulness } & \multicolumn{2}{|c|}{0.090} & 0.012 & 0.189 \\
\hline Weekly reducing hindrance leisure demands & \multicolumn{2}{|c|}{ Weekly physical thriving } & \multicolumn{2}{|c|}{-0.005} & -0.053 & 0.031 \\
\hline Weekly reducing hindrance leisure demands & \multicolumn{2}{|c|}{ Weekly mental health } & \multicolumn{2}{|c|}{-0.016} & -0.105 & 0.064 \\
\hline Weekly reducing hindrance leisure demands & \multicolumn{2}{|c|}{ Weekly life meaningfulness } & \multicolumn{2}{|c|}{-0.010} & -0.084 & 0.054 \\
\hline
\end{tabular}

Note: Bold values refer to the confidence intervals that are not include zero. 


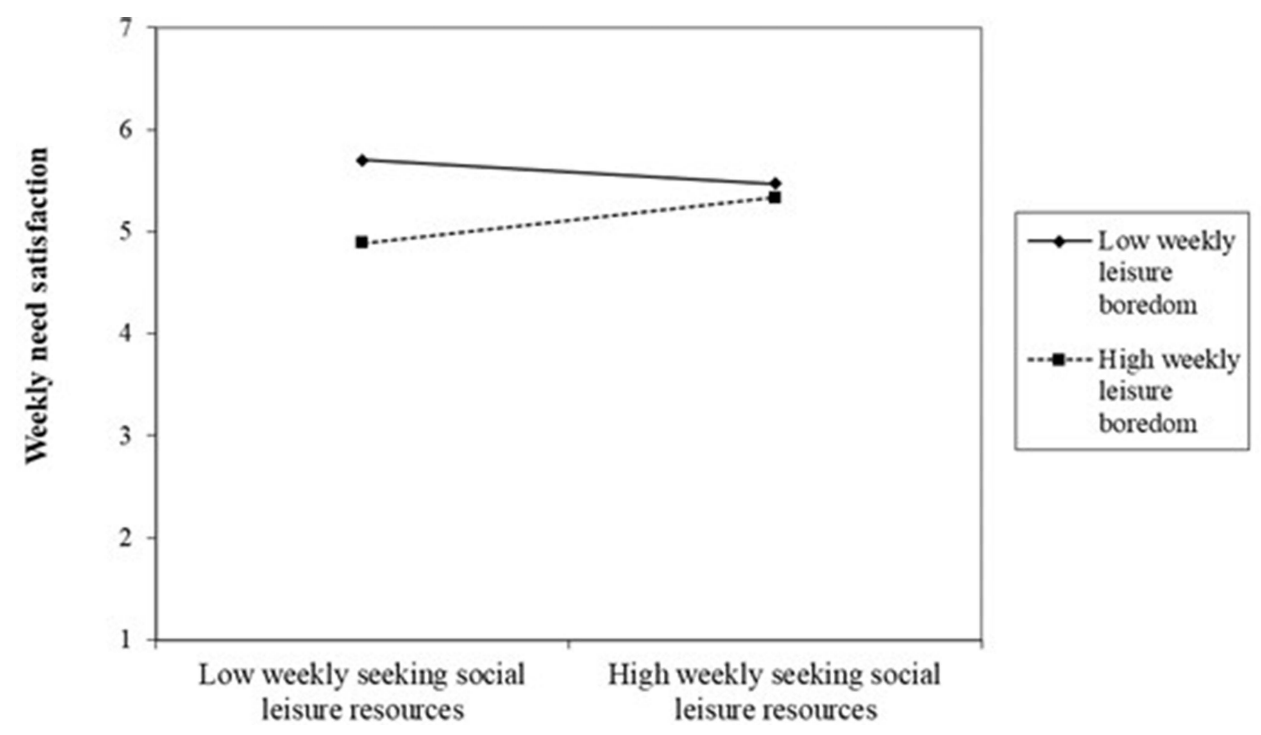

Figure $\mathbf{2}$ The interaction between weekly seeking social leisure resources and weekly leisure boredom on weekly need satisfaction.

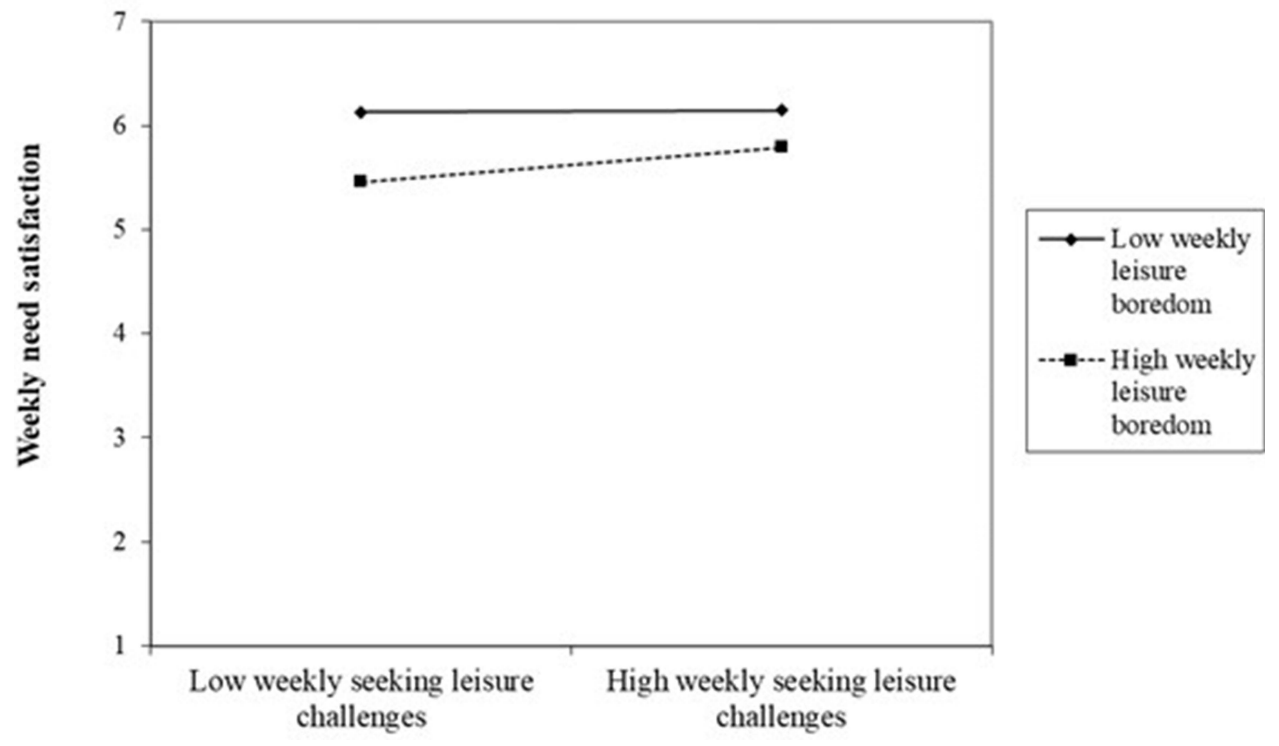

Figure 3 The interaction between weekly seeking leisure challenges and weekly leisure boredom on weekly need satisfaction.

well-being. Age did have the negative effects on the leisure crafting and need satisfaction. Thus, our findings suggest that leisure crafting is an efficient strategy for college students to take charge and shape their leisure lives because it involves a more motivational process and enables individuals to customize and adjust their leisure resources and barriers aligning with their own needs, interests, and preferences. In addition, leisure crafting plays a compensating role when college students are in an unfavorable personal state (eg, boredom), which implies that leisure crafting is able to offset the negative impact of leisure boredom efficiently and enables individuals to stay in a more engaged and active state.

\section{Theoretical Implications}

We first add to the college student well-being and development ${ }^{1,8}$ literature by focusing on the leisure context and highlighting a proactive, strategical means to improve college students' well-being. The mainstream studies focused on how to stimulate students to engage in learning in the study context, such as creating a more supportive, inclusive study 
environment, ${ }^{4,30}$ providing various educational programs, courses, and activities, ${ }^{3}$ and cultivating students' learningoriented strategies. ${ }^{5,8}$ Recent studies called for a better understanding of the utilization of college students' leisure context. ${ }^{15,17}$ Our study thus answers this call by unfolding a leisure management strategy - leisure crafting. Incorporating the resources-demands perspective, ${ }^{21}$ we underscore that it is important for college students to actively craft their leisure resources (eg, structural resources and social resources) and demands (eg, challenging demands and hindering demands). A small number of studies identified that employees could enhance their work engagement and reduce work stress by crafting their leisure time. ${ }^{20,23}$ We point out that in the college setting, leisure crafting is still an effective and important strategy for college students to have a (physically and mentally) healthy, meaningful life. College students could profit from their leisure time by actively customizing their leisure resources and demands.

Second, we add to the leisure management literature ${ }^{7,16}$ by proposing a more holistic, goal-oriented strategy - leisure crafting - manage one's leisure conditions. Traditional studies identified valuable leisure activities such as sports, reading, and traveling for improving one's leisure life. ${ }^{16-19}$ Our study suggests that leisure crafting is not just a single leisure activity but a series of small meaningful adjustments in the leisure context based on one's own leisure situations, interests, and goals. Compared to traditional spontaneous, one-fits-all actions, leisure crafting is a more goal-directed, proactive, and customized way to shape one's leisure circumstances. More importantly, we followed the resourcesdemands perspective ${ }^{21}$ to provide specific strategies students can take to manage their leisure lives. Thus, we shed lights on how students can craft their leisure lives. Specifically, our results showed that four leisure crafting behaviors - seeking structural leisure resources, seeking social leisure resources, seeking leisure challenges, and reducing hindering leisure demands - are effective in satisfying one's intrinsic needs and consequently improving physical, mental health and meaningfulness. Thus, we highlight that leisure crafting is a more proactive process by which individuals mobilize their leisure (structural, social) resources and optimize those detriments. Leisure crafting seems to follow the philosophy of "which size fits you" rather than "one size fits all".

Third, conducting a weekly diary study, we gain insights into a more dynamic process of leisure crafting on college students' well-being. That is, we not only capture how leisure crafting actions vary between individuals but also reveal how leisure crafting actions vary and influence the changes of well-being over time within individuals. This is not simply methodologically advanced, but also with theoretical insights. ${ }^{27}$ College students experience different study tasks, social activities, and personal feelings across days and weeks. They also have different needs, preferences, and interests in their leisure lives across different days/weeks. Conducting a weekly diary study, we capture how students make small adjustments in their leisure resources and detriments over time ${ }^{7}$ and further improve their well-being. This gives us more insights into how leisure crafting as an ongoing, dynamic process, instead of a single-time event, facilitates the level of college students' well-being over time.

Fourth, we uncover the compensating role of leisure crafting when individuals are in an unfavorable personal state. We enrich the free-time boredom management literature ${ }^{45,46}$ by highlighting that leisure crafting is a more effective strategy for individuals who have a higher leisure boredom perception. Specifically, our results showed that two of the four leisure crafting behaviors - seeking social leisure resources and seeking leisure challenges - were more effective in enhancing need satisfaction and consequently improving leisure life outcomes. That is, increasing social resources and challenging demands in leisure time are particularly helpful for buffering the negative impact of leisure boredom. We provide valuable insights into when leisure crafting plays a more beneficial role in college students' leisure life. Prior studies found that leisure crafting plays a compensating role for workers in the work setting (eg, to buffer the negativity of job stress) ${ }^{20,23}$ Our study uncovers that leisure crafting has a similar compensating role for college students in the school setting, ie, to offset the negativity of leisure boredom.

Finally, we also provide valuable insights into the family engagement and work-family literature ${ }^{34,52}$ by highlighting that students' leisure crafting might be a valued means to create family harmony. The family engagement literature indicates that families should actively engage in students' college life and provide sufficient support. ${ }^{52,53}$ Our study points out that students themselves could also engage in some actions to facilitate family relationships. For example, seeking more social leisure resources (an aspect of leisure crafting) can be a way to achieve that family-based goal. Likewise, the work-family/non-work literature uncovered various approaches to increase family life quality and reduce 
family conflict (eg, parents' involvement, communality roles, religious roles). ${ }^{34}$ Our study underscores that students may be another vital role and that students actively crafting the leisure context could be beneficial to the family facilitation.

\section{Practical Implications}

Our study also provides valuable practical implications for college practitioners and students. First, our study indicates that leisure crafting is a proactive process of customizing leisure resources and demands. Therefore, we suggest that college practitioners provide students with more available leisure resources, such as ample channels/facilities to learn and develop new hobbies, skills, and abilities; a variety of platforms and activities to build social connections with others. For students themselves, we suggest that they craft their leisure lives in a proactive and customized manner. For example, students can proactively learn new things they are interested in and develop a new habit that can have positive, lasting effects. As such, they can gain different structural resources in their leisure life and increase their intrinsic need satisfaction. Students can also proactively build good relationships with others; seek help, emotional support, and useful information from others. As such, they can gain valuable social resources in their leisure life. Besides the expandoriented leisure crafting, students can also engage in avoid-oriented leisure crafting strategy, such as reducing hindering leisure demands. For example, when a leisure activity is too dangerous, meaningless, or energy-consuming, and/or someone is bullying, bringing too much negativity, students can purposefully and strategically reduce these activities and avoid these people. As such, they can gain a more healthy, peaceful leisure life. Besides, our results showed that leisure crafting was an effective strategy to offset the negative impact of leisure boredom perceptions. Thus, we recommend that college students initiate leisure crafting actions when they perceive high boredom in their leisure time. By doing so, they could be able to obtain higher need satisfaction, and improve their physical, mental well-being and meaningfulness.

Second, students' well-being is important as part of their college experience. It is essential because their well-being and academic excellence are intertwined. High well-being students are more resilient and have more energy to attain study goals and challenges. Schools should, therefore, not only be a place for students to learn. They should also be a place where students' well-being is prioritized, while still delivering excellent instruction and learning activities. Thus, it becomes more important for universities to take actions to increase students' well-being. In our study, we suggest that developing a leisure crafting intervention program can be an effective means to teach students to enhance well-being via crafting their leisure context. We suggest that future studies can and should develop an intervention program to train and teach students' leisure crafting behaviors. In the work domain, some scholars proposed and developed relevant intervention program to train employees' crafting behaviors. ${ }^{37}$ Following the same logic, providing necessary training or guidance is important for students to learn and practice leisure crafting strategy. Via training, students can increase awareness of engaging in leisure crafting and get to know how to craft in a self-regulatory manner. This would provide more practical implications for education sectors and students themselves.

\section{Limitations and Future Directions}

Our study also has certain limitations, which represent fruitful future directions. First, all the constructs were self-reported, which might cause the common method bias (eg, social desirability bias). However, we conducted a diary study with repeated measures, which might alleviate such issues. The methodology scholars indicate that common method bias is less likely to be a serious concern when interaction effects are observed and when constructs are measured over time. ${ }^{26,27}$ Nevertheless, we recommend that future studies can use other-ratings (eg, teachers' rate, peers' rate, or parents' rate) to measure students' leisure crafting behaviors, to increase the validity of the measurement. Second, we recruited our participants from a single university in a Chinese context. The students were all from an engineering college and the majority of them were male. This might be a limitation of this study as it may raise a concern of the result generalizability. However, as we conducted a short-term longitudinal study, we believe our findings can be applied to other background students and other country settings. We recommend that future studies can replicate our model, design, and results. Third, although we provide insights into the beneficial effects of leisure crafting on college students' well-being, we strongly recommend that future studies can develop relevant intervention programs to stimulate students' leisure crafting behaviors. Some studies developed effective interventions in the work setting, such as job crafting behaviors. ${ }^{37}$ We believe that it is valuable to develop a leisure crafting intervention for students. That said, we can provide a manageable tool for students and educational managers to use to shape leisure lives and enhance well-being. 


\section{Conclusion}

In conclusion, this study sheds light on how and when college students engage in leisure crafting to facilitate their leisure life. Conducing a weekly diary study, we uncovered a dynamic process of how leisure crafting enhances one's well-being via increasing intrinsic need satisfaction; and how leisure crafting was more beneficial for those who had a higher level of leisure boredom. Our study highlights that (1) leisure crafting is a proactive process by which individuals customize and adjust their leisure resources and barriers aligning with their own needs, interests, and preferences, and that (2) leisure crafting plays a compensating role when one is in an unfavorable personal state (eg, leisure boredom).

\section{Acknowledgments}

All procedures performed in this study were in accordance with American Psychological Association (APA) ethical regulations regarding the treatment of human participants. This study was conducted in accordance with the ethical guidelines of the Ethics Committee of the University of Jinan, with written informed consent from all subjects. All the participants were asked to read and approve this ethical consent before taking part in the present study and followed it in the process of research. The protocol was approved by the Ethics Committee of the University of Jinan.

\section{Author Contributions}

All authors made substantial contributions to conception and design, acquisition of data, or analysis and interpretation of data; took part in drafting the article or revising it critically for important intellectual content; agreed to submit to the current journal; gave final approval of the version to be published; and agree to be accountable for all aspects of the work. The data can be obtained via request from the corresponding author.

\section{Disclosure}

The authors report no conflicts of interest in this work.

\section{References}

1. Doerksen SE, Elavsky S, Rebar AL, Conroy DE. Weekly fluctuations in college student leisure activities and well-being. Leis Sci. 2014;36 (1):14-34. doi:10.1080/01490400.2014.860778

2. Auerbach RP, Alonso J, Axinn WG, et al. Mental disorders among college students in the World Health Organization World Mental Health Surveys. Psychol Med. 2016;46(14):2955-2970. doi:10.1017/S0033291716001665

3. Jaggars S, Bailey TR. Effectiveness of fully online courses for college students: response to a department of education meta-analysis. 2010. doi:10.7916/D85M63SM.

4. Pitcher EN, Camacho TP, Renn KA, Woodford MR. Affirming policies, programs, and supportive services: using an organizational perspective to understand LGBTQ college student success. J Divers High Educ. 2018;11(2):117-132. doi:10.1037/dhe0000048

5. Chase JA, Houmanfar R, Hayes SC, Ward TA, Vilardaga JP, Follette V. Values are not just goals: online ACT-based values training adds to goal setting in improving undergraduate college student performance. J Context Behav Sci. 2013;2(3-4):79-84. doi:10.1016/j.jcbs.2013.08.002

6. Chessman H, Taylor M. College student mental health and well-being: a survey of presidents - higher education today; 2019. Available from: https://www.higheredtoday.org/2019/08/12/college-student-mental-health-well-survey-college-presidents/. Accessed August 14, 2021.

7. Tsaur SH, Yen CH, Yang MC, Yen HH. Leisure crafting: scale development and validation. Leis Sci. 2020;1-21. doi:10.1080/ 01490400.2020 .1783728

8. Wang H, Yang J, Li P. How and when goal-oriented self-regulation improves college students' well-being: a weekly diary study. Curr Psychol. 2021;1-12. doi:10.1007/s12144-020-01288-w

9. Parker SK, Bindl UK, Strauss K. Making things happen: a model of proactive motivation. J Manage. 2010;36(4):827-856. doi:10.1177/ 0149206310363732

10. Luthans F, Youssef CM, Avolio BJ. Psychological Capital: Developing the Human Competitive Edge. Oxford: Oxford University Press; 2007. doi:10.1093/acprof:oso/9780195187526.001.0001

11. Laranjo L, Lau AYS, Martin P, Tong HL, Coiera E. Use of a mobile social networking intervention for weight management: a mixed-methods study protocol. BMJ Open. 2017;7(7):e016665. doi:10.1136/bmjopen-2017-016665

12. Stupnisky RH, Perry RP, Renaud RD, Hladkyj S. Looking beyond grades: comparing self-esteem and perceived academic control as predictors of first-year college students' well-being. Learn Individ Differ. 2013;23(1):151-157. doi:10.1016/J.LINDIF.2012.07.008

13. Schmuck P, Kasser T, Ryan RM. Intrinsic and extrinsic goals: their structure and relationship to well-being in German and U.S. college students. Soc Indic Res. 2000;50:225-241. doi:10.1023/A:1007084005278

14. Wang JL, Jackson LA, Gaskin J, Wang HZ. The effects of Social Networking Site (SNS) use on college students' friendship and well-being. Comput Human Behav. 2014;37:229-236. doi:10.1016/J.CHB.2014.04.051

15. Molina-García J, Castillo I, Queralt A. Leisure-time physical activity and psychological well-being in university students. Psychol Rep. 2011;109 (2):453-460. doi:10.2466/06.10.13.PR0.109.5.453-460 
16. Chan WY, Rodriguez A, Shih RA, et al. How do college students use their free time? A latent profile analysis of leisure activities and substance use. Leis Sci. 2020;1-20. doi:10.1080/01490400.2020.1829520

17. Yarnal C, Qian X, Hustad J, Sims D. Intervention for positive use of leisure time among college students. J Coll Character. 2013;14(2):171-176. doi: $10.1515 /$ jcc-2013-0022

18. Finlay AK, Ram N, Maggs JL, Caldwell LL. Leisure activities, the social weekend, and alcohol use: evidence from a daily study of first-year college students. Alcohol Drugs. 2012;73:250-259. doi:10.15288/jsad.2012.73.250

19. Beutel ME, Brähler E, Glaesmer H, Kuss DJ, Wölfling K, Müller KW. Regular and problematic leisure-time internet use in the community: results from a German population-based survey. Cyberpsychol Behav Soc Netw. 2011;14:291-296. doi:10.1089/cyber.2010.0199

20. Petrou P, Bakker AB. Crafting one's leisure time in response to high job strain. Hum Relations. 2016;69(2):507-529. doi:10.1177/ 0018726715590453

21. Bakker AB, Demerouti E. Job demands-resources theory: taking stock and looking forward. J Occup Health Psychol. 2017;22(3):273-285. doi:10.1037/ocp0000056

22. Berg JM, Grant AM, Johnson V. When callings are calling: crafting work and leisure in pursuit of unanswered occupational callings. Organ Sci. 2010;21(5):973-994. doi:10.1287/orsc.1090.0497

23. Petrou P, Bakker AB, van den Heuvel M. Weekly job crafting and leisure crafting: implications for meaning-making and work engagement. J Occup Organ Psychol. 2017;90(2):129-152. doi:10.1111/joop.12160

24. Deci EL, Ryan RM. Self-determination theory: a macrotheory of human motivation, development, and health. Can Psychol. 2008;49(3):182-185. doi:10.1037/a0012801

25. Crant JM. Proactive behavior in organizations. J Manage. 2000;26(3):435-462. doi:10.1177/014920630002600304

26. Gabriel AS, Podsakoff NP, Beal DJ, et al. Experience sampling methods: a discussion of critical trends and considerations for scholarly advancement. Organ Res Methods. 2019;22(4):969-1006. doi:10.1177/1094428118802626

27. Ohly S, Sonnentag S, Niessen C, Zapf D. Diary studies in organizational research: an introduction and some practical recommendations. $J$ Pers Psychol. 2010;9(2):79-93. doi:10.1027/1866-5888/a000009

28. Korkutata A. Leisure boredom scale: a research on university students. J Educ Train Stud. 2018;6(12):148. doi:10.11114/jets.v6i12.3648

29. Rüppel F, Liersch S, Walter U. The influence of psychological well-being on academic success. J Public Health (Bangkok). 2015;23(1):15-24. doi:10.1007/s10389-015-0654-y

30. Shin JY, Steger MF. Supportive college environment for meaning searching and meaning in life among American college students. J Coll Stud Dev. 2016;57(1):18-31. doi:10.1353/csd.2016.0005

31. Hardy SA, Francis SW, Zamboanga BL, Kim SY, Anderson SG, Forthun LF. The roles of identity formation and moral identity in college student mental health, health-risk behaviors, and psychological well-being. J Clin Psychol. 2013;69(4):364-382. doi:10.1002/jclp.21913

32. Martin M, Harris M, Martin D. The relationship between psychological well-being and perceived wellness in graduate-level counseling students. High Learn Res Commun. 2013;3(2):14. doi:10.18870/hlrc.v3i2.91

33. Stebbins RA. Serious leisure. Society. 2001;38(4):53-57. doi:10.1007/s12115-001-1023-8

34. Frone MR. Work-family balance. In: Handbook of Occupational Health Psychology. American Psychological Association; 2003:143-162.

35. Slemp GR, Vella-Brodrick DA. Optimising employee mental health: the relationship between intrinsic need satisfaction, job crafting, and employee well-being. J Happiness Stud. 2014;15(4):957-977. doi:10.1007/s10902-013-9458-3

36. Van Den Broeck A, Ferris DL, Chang C-H, Rosen CC. A review of self-determination theory's basic psychological needs at work. $J$ Manage. 2016;42(5):1195-1229. doi:10.1177/0149206316632058

37. van Wingerden J, Bakker AB, Derks D. Fostering employee well-being via a job crafting intervention. J Vocat Behav. 2017;100:164-174. doi:10.1016/j.jvb.2017.03.008

38. Kinoshita K, Macintosh E, Sato S. Thriving in youth sport: the antecedents and consequences. Int J Sport Exerc Psychol. 2021;1-21. doi:10.1080/ 1612197X.2021.1877327

39. Ghitulescu BE. Making change happen: the impact of work context on adaptive and proactive behaviors. J Appl Behav Sci. 2012;49(2):206-245. doi: $10.1177 / 0021886312469254$

40. Wang H-J, Demerouti E, Le Blanc P, Lu C-Q. Crafting a job in "tough times": when being proactive is positively related to work attachment. J Occup Organ Psychol. 2018;91:569-590. doi:10.1111/joop.12218

41. Hobfoll SE, Halbesleben J, Neveu JP, Westman M. Conservation of resources in the organizational context: the reality of resources and their consequences. Annu Rev Organ Psychol Organ Behav. 2018;5:103-128. doi:10.1146/annurev-orgpsych-032117-104640

42. Haller M, Hadler M, Kaup G, Haller M, Kaup ÁG, Hadler M. Leisure time in modern societies: a new source of boredom and stress? Soc Indic Res. 2013;111:403-434. doi:10.1007/s11205-012-0023-y

43. Spruyt B, Vandenbossche L, Keppens G, Siongers J, Van Droogenbroeck F, Van Droogenbroeck Filipvandroogenbroeck F. Social differences in leisure boredom and its consequences for life satisfaction among young people. Child Ind Res. 2018;11:225-243. doi:10.1007/s12187-016-9430-y

44. Iso-Ahola SE, Weissinger E. Perceptions of boredom in leisure: conceptualization, reliability and validity of the leisure boredom scale. $J$ Leis Res. 1990;22(1):1-17. doi:10.1080/00222216.1990.11969811

45. Wang W-C. Exploring the relationship among free-time management, leisure boredom, and internet addiction in undergraduates in Taiwan. Psychol Rep. 2019;122(5):1651-1665. doi:10.1177/0033294118789034

46. Wang W-C, Wu -C-C, Wu C-Y, Huan T-C. Exploring the relationships between free-time management and boredom in leisure. Psychol Rep. 2012;110:416-426. doi:10.2466/13.17.PR0.110.2.416-426

47. Bolger N, Laurenceau JP. Intensive Longitudinal Methods: An Introduction to Diary and Experience Sampling Research. New York: Guilford; 2013.

48. Sheldon KM, Elliot AJ, Kim Y, Kasser T. What is satisfying about satisfying events? Testing 10 candidate psychological needs. J Pers Soc Psychol. 2001;80(2):325-339. doi:10.1037/0022-3514.80.2.325

49. Steger M, Frazier P, Oishi S, Kaler M. The meaning in life questionnaire: assessing the presence of and search for meaning in life. $J$ Couns Psychol. 2006;53(1):80-93. doi:10.1037/0022-0167.53.1.80

50. Solberg E, Wong SI. Crafting one's job to take charge of role overload: when proactivity requires adaptivity across levels. Leadersh Q. 2016;27 (5):713-725. doi:10.1016/j.leaqua.2016.03.001 
51. Rockwood NJ, Hayes AF. MLmed: An SPSS Macro for Multilevel Mediation and Conditional Process Analysis. Boston, MA.: Association of Psychological Science (APS); 2017.

52. Marrun NA. "My mom seems to have a dicho for everything!": family engagement in the college success of Latina/o students. $J$ Latinos Educ. 2018;19(2):164-180. doi:10.1080/15348431.2018.1489811

53. DeSpain S, Conderman G, Gerzel-Short L. Fostering family engagement in middle and secondary schools. Clear House a J Educ Strategy Issues Ideas. 2018;91(6):236-242. doi:10.1080/00098655.2018.1524743

\section{Publish your work in this journal}

Psychology Research and Behavior Management is an international, peer-reviewed, open access journal focusing on the science of psychology and its application in behavior management to develop improved outcomes in the clinical, educational, sports and business arenas. Specific topics covered in the journal include: Neuroscience, memory and decision making; Behavior modification and management; Clinical applications; Business and sports performance management; Social and developmental studies; Animal studies. The manuscript management system is completely online and includes a very quick and fair peer-review system, which is all easy to use. Visit http://www.dovepress.com/testimonials.php to read real quotes from published authors.

Submit your manuscript here: https://www.dovepress.com/psychology-research-and-behavior-management-journal 